\section{Biocontrol of solid surfaces in hospitals using microbial-based wipes}

\author{
Aysin Dural-Erem', Per Wessman ${ }^{2}$, Ulrika Husmark ${ }^{3}$ and \\ Vincent Nierstrasz'
}

Textile Research Journal 2019, Vol. 89(2) 216-222 (C) The Author(s) 2017 Article reuse guidelines: sagepub.com/journals-permissions DOI: $10.1 \mid 77 / 004051751774$ |163 journals.sagepub.com/home/trj

SAGE

\begin{abstract}
Hospital-acquired infections have become a major challenge which threaten the hospitalized patients' safety. The presence of nosocomial pathogens is generally reported in connection with solid surfaces near patient environments. These surfaces become significant sources of transmission and lead most often to the contamination and cross-contamination of nosocomial pathogens to the patients and staff. This paper investigates strategies to apply beneficial bacteria on viscose-based nonwoven wipes and the viability of these beneficial bacteria on the wipes along with characterization of the physical properties of the wipes. Major findings include that it is possible to produce dry wipes which contain an adequate number of beneficial bacteria or spores. After these wipes are wetted, they can release a certain number of bacteria from the wetted wipes. These released beneficial bacteria can inhibit pathogens by growing and colonizing on the wiped surfaces.
\end{abstract}

\title{
Keywords
}

cleaning wipes, Bacillus spore, beneficial spores, beneficial bacteria, antimicrobial coating

Hospital-acquired infections (HAI) are a growing world-wide problem and cause morbidity and mortality for healthcare facilities' patients and staff. According to the definition of the World Health Organization (WHO), HAI are defined as infections developing after $48 \mathrm{~h}$ of hospitalization which do not present or incubate at the time of admission. ${ }^{1}$ Based on Centers for Disease Control and Prevention (CDC) data, in Europe, the incidence rate of HAI has been estimated as $1,444,000$ cases, with up to 148,000 deaths, per year with an estimated cost of $\$ 7.0$ billion annually. ${ }^{2}$ Common nosocomial pathogens such as Clostridium difficile, Staphylococcus aureus, Klebsiella pneumoniae, and Pseudomonas aeruginosa are the main causes of the $\mathrm{HAI}^{3}$ The spreading of HAI is related to noncompliance or breaches of infection control practice or procedures such as improperly processed reusable medical devices and contamination of unclean environmental surfaces. ${ }^{4}$ Wipes are increasingly used as more practical tools for cleaning reusable medical devices, and surfaces help to prevent these breaches and decrease incidence of HAI. Use of wipes for cleaning contamination is more timesaving and practical than traditional cleaning methods. There are major requirements desired in medical wipes, such as rapid absorbency, low static and gliding friction, nonallergic characteristics, and reasonable life. Traditional medical wipes have been tissue based or woven, but with increasing nonwoven production methods such as air laid or wet spun, nonwoven wipes have become more common because of economic concerns and easy production processes. ${ }^{5}$

Many wipes, functionalized with different antimicrobial agents, are used in clinical settings to clean and disinfect low risk equipment and the near patient

\footnotetext{
'Textile Materials Technology, Department of Textile Technology, University of Borås, Sweden

${ }^{2}$ RISE Research Institutes of Sweden, Surface, Process and Formulation, Sweden

${ }^{3}$ SCA Hygiene Products AB, Mölndal, Sweden
}

\section{Corresponding author:}

Aysin Dural-Erem, Textile Materials Technology, Department of Textile Technology, Faculty of Textiles, Engineering and Business, University of Borås, Skaraborgsvägen 3D, Borås SE 506 30, Sweden.

Email: aysin.erem@gmail.com 
environment. These cleaning wipes are used to support a reduction in the transmission of pathogens via the environment, including spore forming pathogenic bacteria and their spores. Their efficacy is strictly related to exposure time and differs depending on their chemical contents. Antimicrobial wipes containing alcohols (generally $70 \%$ isopropanol) or surface-active chemicals (quaternary ammonium compounds (QACs), triclosan, and triamines) are only effective against non-spore forming bacteria. Wipes with chlorine dioxide or peracetic acid are useful to inhibit spores and non-enveloped viruses. ${ }^{4,6}$ An ideal antimicrobial agent should be active against a broad spectrum of microorganisms whilst being nontoxic and nonallergenic. However, there are some of commonly used antimicrobial substrates concerns about the toxicity of surface-active chemical or alcohol. With developments in biotechnology, sustainable alternatives based on biological substrates such as enzymes and beneficial microorganisms have received attention.

According to the Food and Agriculture Organization (FAO) and the WHO, beneficial microorganisms (i.e., probiotics) can be defined as "live microorganisms (bacteria/yeasts), which when ingested or locally applied in sufficient numbers confer one or more specified demonstrated health benefits for the host." 7 Most of the beneficial microorganisms can inhibit pathogens with their antimicrobial or antagonistic ability. Their antagonistic properties can be the result of competitive exclusion, production of hydrogen peroxide, or organic acids that lower $\mathrm{pH}$. Their antimicrobial activity is highly related to their products such as, for instance, bacteriocins or antioxidants. ${ }^{8-10}$ As beneficial bacteria can get involved in the different environments and actively influence the ecology in these environments, they can help to decrease the number of other unwanted (pathogenic) microorganisms. In comparison with the use of other disinfectants, they cannot give as rapid and efficient a decrease of other microbes, but they may have a long term and more lasting positive influence on the microflora in the room. In this way, they may contribute to lowering risks of infection and hence give health benefits to humans staying or living in, for example, a health care facility. There are different ways to introduce beneficial bacteria into an environment, and attaching them during the cleaning process is one of the most efficient routes. After activating in water, dry wipes impregnated with beneficial spores/bacteria can be a good solution to practically clean the surfaces near patients. When they are activated with water, certain amounts of spores/bacteria will be released from the wipe to the wiped solid surfaces, and released spores turn into beneficial bacteria on the surfaces to protect them from pathogens by providing antagonistic/antimicrobial activity. There is certain evidence in previous studies, completed between 2014 and 2016, showing that use of Bacillus spores in cleaning products helps to reduce the number of infection-related pathogens and antibiotic resistant bacteria strains. ${ }^{11,12}$

There have been several attempts to apply beneficial bacteria and spores on textiles to date. Ciera et al. (2014) studied the proper melt spinning conditions for Bacillus spores, and then they produced PET filaments with Bacillus spores by intercalating Bacillus amyloliquefaciens spores in a polymer matrix during the melt spinning process. ${ }^{13,14}$ Henus et al. (2010) succeeded in encapsulating viable Lactobacillus plantarum 423 bacterial cells and their bacteriocin in polyethylene oxide nanofibers. ${ }^{15}$ Traditional textile processes, such as wet processing or dip coating, may be used to develop proper strategies to incorporate beneficial spores/bacteria in nonwoven surfaces. Then these nonwoven surfaces which contain beneficial bacteria/spores may become useful tools to achieve the biocontrol of solid surfaces.

This research aims to assess the potential of beneficial bacteria/spores in functionalization of nonwovens to produce dry probiotic wipes. Incorporation of beneficial bacteria/spores on the viscose-based nonwoven wipes was achieved using two different strategies. One of these strategies was to process the wipes in an impregnation bath with certain amounts of probiotic finishing agent and the other strategy was to coat wipes with certain amounts of probiotic finishing agent. Then the amounts released from each wipe were compared to determine the most promising incorporation strategy.

\section{Experimental}

\section{Material}

Tana ${ }^{\circledR}$ Biotic DC, kindly gifted by Tanatex Chemicals, Netherlands, was used as a finishing agent with beneficial bacteria and poly(ethylene glycol) (PEG) $M_{w} 400$, purchased from Sigma-Aldrich Co, Sweden, was used as a binder in the coating process. Viscose-based spun lace wipes (weight: $60 \mathrm{~g} / \mathrm{m}^{2}$, thickness: $0.60 \mathrm{~mm}$ ) were provided from SCA Hygiene Products AB, Sweden, and used as the textile substrate for all samples.

\section{Preparation of wipes}

Nonwoven wipes were padded twice through a finishing bath containing certain amounts of probiotic finishing agent with a liquid ratio of $1: 10$ then they squeezed in between mangles with a speed of $2 \mathrm{~m} / \mathrm{min}$ and $80 \%$ liquid pick up were achieved. After padding process they were dried at room temperature for $2 \mathrm{~h}$ (Table 
Table I. Ingredients of the impregnation and coating baths

\begin{tabular}{llll}
\hline Sample & PEG & $\begin{array}{l}\mathrm{H}_{2} \mathrm{O} \\
{[\mathrm{mL}]}\end{array}$ & $\begin{array}{l}\text { Tana Biotic } \\
\text { DC }[\mathrm{mL}]\end{array}$ \\
\hline F0 & $400[\mathrm{~mL}]$ & - & - \\
FI & - & 97.5 & 2.5 \\
F2 & - & 75 & 25 \\
P0 & - & 15 & - \\
PI & 15 & 12.5 & 2.5 \\
\hline
\end{tabular}

1). The treated samples were rinsed with distilled water to remove excess and unfixed chemicals and finally dried at room temperature.

Beneficial bacteria and spores are ideal for use in a chemical finishing process as they have a high affinity for textiles and the capability to attach to the textile surfaces without binding agents. Adhesion of bacteria/spores on surfaces is a complex process involving different forces and interactions. Among them, electrostatic and hydrophobic interactions play the most important role in the adhesion of spores to inert surfaces. ${ }^{16,17}$ Incorporating the beneficial bacteria/ spores on wipes in a controlled way that, at the same time, also allows for sufficient release when the wipe is in use is challenging. In order to control the release of bacteria/spores, soluble binders were used in the preparation of coatings to attach the entrapped beneficial bacteria/spores on the wipes. PEG was preferred as a binder because of its unique properties, such as high hydrophilicity, biocompatibility, and non-toxicity. ${ }^{18}$ PEG 400 was dissolved in demineralized water by stirring for $2 \mathrm{~h}$ at room temperature. After it had totally dissolved, the probiotic finishing agent was added to this solution and stirred for $30 \mathrm{~min}$ at $400 \mathrm{rpm}$ at room temperature to obtain a homogeneous solution. Then, nonwoven substrates were dip coated in the prepared solutions for $15 \mathrm{~min}$ and the substrates were transferred to the mangles with a speed of $2 \mathrm{~m} / \mathrm{min}$ to squeeze under a load of $20 \mathrm{~kg} / \mathrm{cm}$. So $100 \%$ liquid pick up were achieved. Finally coated samples were dried at room temperature for $2 \mathrm{~h}$ then cured at $110^{\circ} \mathrm{C}$ for $5 \mathrm{~min}$.

\section{Characterization tests}

To determine the growth of the incorporated bacteria, viability tests were done using sample ready $3 M^{T M}$ Petrifilm $^{T M}$ aerobic count plates which contain the water-soluble gelling agent, nutrients and an indicator that are needed for microbial growth to be indicated by red colored colonies on the plate. Wipes were cut into pieces of size $4 \times 4 \mathrm{~cm}$ and sterilized at $75^{\circ} \mathrm{C}$ for $1 \mathrm{~h}$. Then, the petrifilms were wetted with $1 \mathrm{~mL}$ of demineralized water and the samples were set in the middle of the films. Afterwards, the petrifilms were placed in the oven to be incubated at $32^{\circ} \mathrm{C}$ for $72 \mathrm{~h}$. After the incubation, they were evaluated visually.

Release tests were performed to determine the number of viable bacteria released from each sample. For this purpose, samples of size $5 \times 10 \mathrm{~cm}$ were prepared from each wipe and each sample was put in tubes containing $10 \mathrm{~mL}$ saline. These tubes were vigorously shaken for $1 \mathrm{~min}$ and held for $15 \mathrm{~min}$. Then, $0.1 \mathrm{~mL}$ of saline solution was taken from each tube and spread on TSA agar plates. These agar plates were incubated at $32^{\circ} \mathrm{C}$ for $24 \mathrm{~h}$. After incubation, the number of colonies growing on each agar plate was counted. The wettability of the fabrics was evaluated using a Attension Theta Optical Tensiometer (Biolin Scientific Ab). The test was conducted using a water droplet size of $3 \mu \mathrm{L}$ and the angle of the drop was measured after 0.5 seconds. Each measurement was repeated at least five times per sample. The vertical wicking rates of the wipes were tested according to DIN 53924. Prior to the vertical wicking tests, samples were conditioned under standard atmospheric conditions. Then the samples were cut into strips of $200 \times 25 \mathrm{~mm}$. They were marked and suspended vertically by their bottom ends and the rising height was measured after $10 \mathrm{~s}$. Then, the average value of all measurements was calculated as the final result. Samples were tested for abrasion in a Cromocol, Martindale 2000 abrasion tester according to the EN ISO 12947-2AC:2006 standard. Before the abrasion tests, two test specimens $(d=4 \mathrm{~cm})$ were prepared from all samples and rested in a conditioned room for $24 \mathrm{~h}$. A force of $9 \mathrm{kN}$ was applied in a downward direction for each test specimen. Evaluation of the damage and breakage of fibers and searching for pilling was made at 1000, 2000, 5000, 10,000, 15,000, and 20,000 rubs by visual analysis. Tension tests were performed using a Tensolab (Mesdab S.p.A) tension machine according to ISO 13934-1:2013. Test specimens were prepared in pieces of $5 \times 15 \mathrm{~cm}$ in size in the machine direction of the wipes. A tension machine set to $100 \mathrm{~mm} / \mathrm{min}$ and a $5 \mathrm{kN}$ force was used. Mean tensile strength and mean elongation values were determined.

\section{Results and discussion}

The success of the embedding process of beneficial spores is highly related to their viability after impregnation and dip coating processes. The viability of the bacteria was determined with $3 M^{T M}$ Petrifilm ${ }^{T M}$ Aerobic Count (AC) plates. After $72 \mathrm{~h}$ incubation, the petrifilms were observed and bacteria colonies were clearly seen as red dots on the samples (Table 2).

The amounts of beneficial bacteria released from the wipes were measured to evaluate their efficiency. 
Table 2. Viability of the beneficial bacteria on the wipes

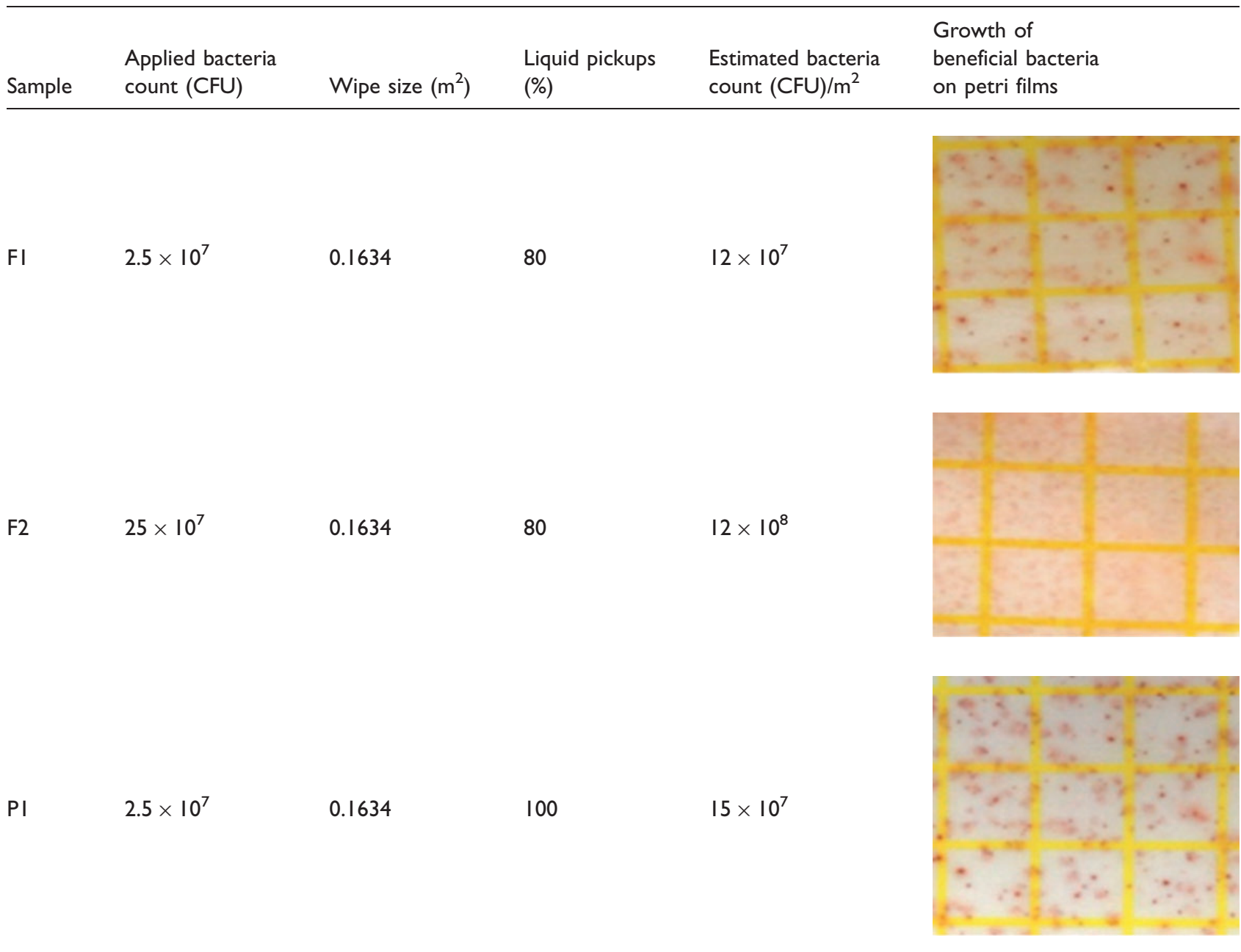

CFU: colony forming units.

When the numbers of beneficial bacteria on the solid surfaces reach certain levels, they can exhibit an inhibitory effect against pathogens. The inhibition mechanisms of beneficial bacteria may be due to their antagonistic capability, as well as their ability to produce antimicrobial compounds. While their antimicrobial activity can be related to the production of bacteriocins, their antagonistic activity against the pathogens can be related to competitive exclusion or to production of compounds that lower the $\mathrm{pH}$ of the environment, such as organic acids and hydrogen peroxides. ${ }^{8,19}$ The beneficial spores that deposited on the surfaces upon wiping can germinate, then grow out to vegetative cells and compete with pathogens or release efficient amounts of antimicrobial substrates to exhibit efficient activity. The release results of the samples are summarized in Figure 1. These results show that it is possible to apply beneficial bacteria as spores using the impregnation process as the spores have a high affinity for textiles and the capability to attach to the textile surfaces without binding agents; however, it is difficult to obtain certain release amounts with the impregnation method. Water soluble binders such as PEG may be an alternative to attach more spores on the wipes and, at the same time, control their release from the wipes.

To evaluate the usability of the wipes, their wettability and wicking were explored. To determine the wettability of the wipes, the water contact angles $(\Theta)$ were measured and the results are summarized in Table 3. The contact angle results of untreated and treated wipes exhibit a high wettability.

The results revealed that the probiotic finishing agent didn't have a significant effect on the wettability of the wipes and did not convert their hydrophilic structure to hydrophobic. On the contrary, the PEG binder used in coated wipes significantly increased the wettability of the wipes $(p<0.05)$. According to Zhang, 


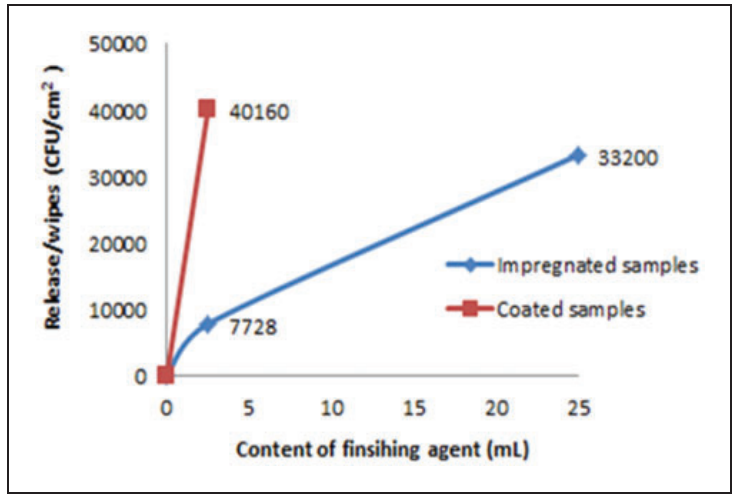

Figure I. Release results of the samples.

Table 3. Wettability results of the samples

\begin{tabular}{lll}
\hline Sample & $\Theta$ mean $\left({ }^{\circ}\right)$ & Time $(\mathrm{s})$ \\
\hline F0 & $36.7 \pm 17.5$ & 1.29 \\
FI & $39.4 \pm 15.7$ & 5.00 \\
F2 & $40.7 \pm 15.8$ & 5.67 \\
P0 & $19.4 \pm 8.3$ & 1.42 \\
PI & $16.7 \pm 6.3$ & 1.08 \\
\hline
\end{tabular}

Table 4. Vertical wicking rate measurements of the wipes

\begin{tabular}{ll}
\hline Sample & $\begin{array}{l}\text { Vertical wicking } \\
\text { rate }(\mathrm{mm})\end{array}$ \\
\hline F0 & $36 \pm 12.99$ \\
FI & $33 \pm 10.02$ \\
F2 & $30 \pm 10.27$ \\
P0 & $29 \pm 13.75$ \\
PI & $27 \pm 18.61$ \\
\hline
\end{tabular}

absorbency is the key property of nonwovens used in wipes, especially for medical wipes, which include hard surface antibacterial, bathing, and incontinence wipes and are designed for use in hospital and health care facilities. ${ }^{20}$ The results of vertical wicking rate measurements are presented in Table 4 . The results showed that the samples with finishing agent and PEG based coating exhibited lower vertical wicking rates than pure viscose-based wipes. This may be due to the filling effect of the finishing agent and coating solutions. When the finishing agent and PEG based coating filled the pores in the wipes' structure, this prevented movement of the water through them as the wicking properties of the wipes are mainly related to the porosity of the wipes. ${ }^{21}$
Table 5. Tensile properties of the samples

\begin{tabular}{lll}
\hline Sample & Max force $(\mathrm{N})$ & Elongation $(\%)$ \\
\hline F0 & $32.30 \pm 2.5$ & $25 \pm 1.0$ \\
FI & $20.60 \pm 3.0$ & $25 \pm 5.0$ \\
F2 & $17.00 \pm 2.6$ & $35 \pm 3.5$ \\
P0 & $57.40 \pm 2.6$ & $28 \pm 1.5$ \\
PI & $83.70 \pm 1.5$ & $26 \pm 1.0$ \\
\hline
\end{tabular}

Table 6. Abrasion properties of the samples

\begin{tabular}{lll}
\hline Sample & No. of revolutions & Damage rating \\
\hline F0 & 1000 & 2, slight \\
& 3000 & 4, severe \\
& 6000 & $60 \%$ degraded \\
FI & 1000 & 3, moderate \\
& 3000 & 4, severe \\
& 4000 & $60 \%$ degraded \\
F2 & 1000 & 3, moderate \\
& 3000 & 4, severe \\
& 4000 & $60 \%$ degraded \\
P0 & 1000 & 2, slight \\
& 3000 & 3, moderate \\
& 6000 & $30 \%$ degraded \\
PI & 1000 & 2, slight \\
& 3000 & 3, moderate \\
& 6000 & $50 \%$ degraded
\end{tabular}

The tensile behavior of the wipes is crucial in determining their end uses and durability. The tensile behavior of the wipes differs depending on the nature of the wipes and their stability to different process conditions, such as dip coating, padding, and thermal treatments. In Table 5, the tensile properties of the wipes are summarized as an average of five test specimens from each sample. According to these results, the samples treated with the finishing agent during padding exhibited lower tensile strengths and higher elongation at break.

In contrast, the samples prepared with dip coating have a higher tensile strength and elongation at break as the coating process contributed to the compactness of the wipes. According to Masteikaite and Saceviciene, this is due to the spaces between fibers being filled up with coating materials. ${ }^{22}$

The abrasion resistance of the wipes is also important for their quality and end use performance. Both the abrasion resistance and lint release properties of wipes are major parameters in using them for special purposes, such as clean room and other medical 
applications, where contaminated environments are highly undesirable. ${ }^{5}$ Wipes with low abrasion resistance may cause high lint release and they may dirty the surfaces instead of cleaning them. When we compared the abrasion resistance of treated wipes with untreated ones, the abrasion resistance test results paralleled the tensile strength tests. The coated wipes showed better resistance, while impregnated samples exhibited a low resistance compared to untreated samples (Table 6).

Kothari and Loganathan tested different commercial wipes which were used in medical applications, and they determined that viscose-based wipes had better absorbency but worse abrasion resistance and lint release properties compared to others. ${ }^{5}$

\section{Conclusion}

This study suggests that nonwovens can be loaded with Bacillus spores and used for cleaning in health care environments. For this purpose, different strategies were developed for attaching spores to nonwoven fibers. The adhesion of the spores on dry wipes was achieved with applied processes. Adhesion between the spores and the fibers in the dry wipes was achieved. However, the controlled release of the spores from the wipes after they were wetted is still challenging. The comprehensive comparison between the release properties of coated and impregnated wipes showed that coated wipes had better performance than others. Furthermore, the coating process improved the physical properties of the wipes. These findings reveal that all samples exhibited a certain amount of release, and these amounts were highly related to the nature of the applied finishing agents and the parameters of the application methods. By the incorporation of probiotics/beneficial spores in the nonwoven wipes, they become a reservoir of beneficial bacteria. When the wipes are used to clean solid surfaces, beneficial bacteria released from them can settle on these cleaned surfaces and provide an antagonistic/antimicrobial effect against nosocomial pathogens.

Based on the data obtained from the present study, a further study is underway which will focus on improving the release mechanism and wiping tests to determine the inhibition mechanism against the common nosocomial pathogens Clostridium difficile, Staphylococcus aureus, Klebsiella pneumoniae, and Pseudomonas aeruginosa.

\section{Acknowledgements}

This research is performed in the framework of the I-Tex project (Intelligent Användning av Innovativa Textilier för en friskare patientnära sjukhusmiljö/intelligent use of innovative textiles for a healthier hospital environment). The authors want to acknowledge Innu Science and Steve Teasdale as being important speaking partners and sharing insights on the potential and requirements when developing spore containing cleaning products. The authors would like to thank Tanatex Chemical, Netherlands, for supplying the probiotic finishing agent for our experiments.

\section{Declaration of conflicting interests}

The authors declared no potential conflicts of interest with respect to the research, authorship, and/or publication of this article.

\section{Funding}

The authors disclosed receipt of the following financial support for the research, authorship, and/or publication of this article: The I-Tex project is supported by a grant of Vinnova (2014-00719).

\section{References}

1. Ducel G, Fabry J and Nicolle L. Prevention of hospitalacquired infections: A practical guide. Malta: World Health Organization Department of Communicable Disease, Surveillance, and Response, 2002, pp.1-64.

2. European Centre for Disease Prevention and Control, Annual epidemiological report on communicable diseases in Europe 2008. Stockholm, Sweden: European Centre for Disease Prevention and Control, 2008. Available online at: http://ecdc.europa.eu/en/publications/ Publications/0812_SUR_Annual_Epidemiologyogical_ Report_2008.pdf (accessed 19 October 2016).

3. Rozman U, Fijan S, Turk SS, et al. Real-time polymerase chain reaction for quantitative assessment of common pathogens associated with healthcare-acquired infections on hospital textiles. Text Res $J$ 2013; 83: 2032-2041.

4. Nandy P, Lucas AD and Gonzalez EA. Efficacy of commercially available wipes for disinfection pulse oximeter sensors. Am J Infect Control 2016; 44: 304-310.

5. Kothari VK and Loganathan R. Lint release characteristics of nonwoven wipes. In: Anand SC and Kennedy JK (eds) Medical and healthcare textiles. Cambridge, UK: Woodhead Publishing Limited, 2010.

6. Royal College of Nursing. The selection and use of disinfectant wipes. London: UK, 2011.

7. FAO/WHO, Joint FAO/WHO Working Group Report on Drafting Guidelines for the Evaluation of Probiotics in Food. London, Ontario, Canada, April 30 and May 1, 2002.

8. Saxelin M, Tynkkynen S, Mattila-Sandholm T, et al. Probiotic and other functional microbes: from markets to mechanisms. Curr Opin Biotechnol 2005; 16: 204-211.

9. Millette $\mathrm{M}$, Luquet FM and Lacroix M. In vitro growth control of selected pathogens by Lactobacillus acidophilus-and Lactobacillus casei-fermented milk. Lett Appl Microbiol 2007; 44: 314-319.

10. Ratsep M, Naaber P, Koljalg $S$, et al. Effect of Lactobacillus plantarum strains on clinical isolates of Clostridium difficile in vitro. J Probiotics Health 2014; 2: 119-120.

11. Vandini A, Temmerman R, Frabetti A, et al. Hard surface biocontrol in hospitals using microbial-based cleaning products. PLOS ONE 2014; 9: e108598. 
12. Caselli E, D'Accolti M, Vandini A, et al. Impact of a probiotic-based cleaning intervention on microbiota ecosystem of the hospital surfaces: Focus on the resistome remodulation. PLos ONE 2016; 11: e0148857.

13. Ciera L, Beladjal L, Almeras X, et al. Resistance of Bacillus amyloliquefaciens spores to melt extrusion process conditions. Fibers Text East Eur 2014; 22, 2(104): 102-107.

14. Ciera L, Beladjal L, Almeras X, et al. Morphology and mechanical properties of poly (ethylene terephalate) (PET) fibers embedded with Bacillus amyloliquefaciens spores. Fibers Text East Eur 2014; 22, 2(106): 29-36.

15. Henus TDJ, Botes M and Dicks LMT. Encapsulation of Lactobacillus plantarum 423 and its bacteriocin in nanofibers. Probiotics Antimicrob Proteins 2010; 2: 46-51.

16. Bajpai V, Bajpai S, Jha MK, et al. Microbial adherence on textile materials: review. J Environ Res Dev 2011; 5: 666-672.

17. Ghoine M, Parello D and Granucci C. Adherence of bacterial spores to encrusted fabrics. J Appl Microbiol 1989; 67: 371-376.
18. Harris JM (ed.) Poly (ethylene glycol) chemistry, biotechnical and biomedical applications. New York, USA: Plenum Press, 1992.

19. Ratsep M, Naaber P, Smidt I, et al. Effect of Lactobacillus plantarum strains on clinical isolates of Clostridium difficile in vitro. J Prob Health 2014; 2: 119-124.

20. Zhang D. Nonwoven for consumer and industrial wipes. In: Chapman RA (ed.) Applications of nonwoven in technical textiles. Cambridge, UK: Woodhead Publishing Limited, 2010.

21. Dubrovski PD and Brezocnik M. Porosity and nonwoven fabrics vertical wicking rate. Fiber Polym 2016; 17: 801-808.

22. Masteikaite V and Saceviciene V. Study on tensile properties of coated fabrics and laminates. Indian J Fiber Text Res 2005; 30: 267-272. 